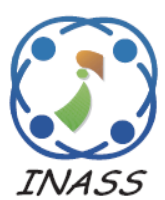

\title{
Compact Antenna for UHF-RFID Tag Tested on the Human Body for Identification Cards
}

\author{
Yassine Gmih ${ }^{1 *}$ \\ Abdelmajid Farchi ${ }^{1}$ \\ ${ }^{1}$ Laboratory of Engineering, Mechanics, Industrial Management and Innovation, \\ Faculty of Sciences and Technologies, University of Hassan 1st, Settat-Morocco \\ * Corresponding author's Email: yassine.gmih@gmail.com
}

\begin{abstract}
This article proposes a new and simple miniaturized tag for radio frequency identification (RFID) in the European and Moroccan UHF band (866-868 MHz). This tag can be mounted on the surfaces of the human body and may be used for identification cards. For human body modelling, we used a four-layer laminated elliptical cylinder with physical parameters for electromagnetic simulations. The radiation characteristics of the antenna placed in proximity to the human model and the effects of absorption caused by the human body were analysed and controlled. Our antenna is composed of a meander dipole and a T-shaped adaptation network structure. We used the CST-MS for the design of the antenna and the human body model and verified the results with the HFSS simulator. The designed tag was manufactured to test the reading range. The measured range is about $6 \mathrm{~m}$ when the tag is placed near to the chest and between hands. The new features of the proposed new tag are characterized by its simple structure, reliable stability on the surface of the human body, a long reading range and a miniaturized size of $46 \mathrm{x} 20 \mathrm{~mm}^{2}$. Our antenna was designed on a low-cost, single-sided FR-4 substrate with a thickness of $0.8 \mathrm{~mm}$. Compared to the conventional ultra-high frequency patch; our antenna achieves a miniaturization rate of $91 \%$.
\end{abstract}

Keywords: RFID, UHF, Tag, Antenna, Meander dipole, Miniaturization, Human body, Read range.

\section{Introduction}

Radio frequency identification or RFID is a rapidly evolving technology for automatic object monitoring and identification. Today, RFID can be implemented in many applications [1] in different fields such as access control, bioengineering, transportation systems, health, inventory management and many more [2]. There are three principal parts to each RFID system. The most important element is the tag or transponder [3], includes an antenna adapted to the ASIC chip (Application-Specific Integrated Circuit) which contains the information. The second is the interrogator reader and its antenna. The last part is generally the database of the application.

RFID is a cordless communication using radio waves from the electromagnetic spectrum. It operates in the unauthorized segment of the spectrum known as ISM (The industrial, scientific and medical).
Frequency, limitations of power, communication protocols and norms may differ in some regions of the world. This is in particular the case of RFID in the UHF band. The operating frequencies are divided into different bands. The data throughput and read ranges are significantly differing from one band to another. Table 1 presents a brief summary of the RFID bands and a number of their useful characteristics [4].

A passive RFID tag (without batteries) consists of two elements, an antenna and a chip. This chip has its proper energy recovery module, so no embedded batteries are required and a unique electronic product code is stored in the EEPROM. Passive ultra-high frequency (UHF) band RFID systems have become much requested in commercial applications because they utilize [5] backscattered wave modulation techniques in order to provide a longer reading distance and better storage capacity for information. 


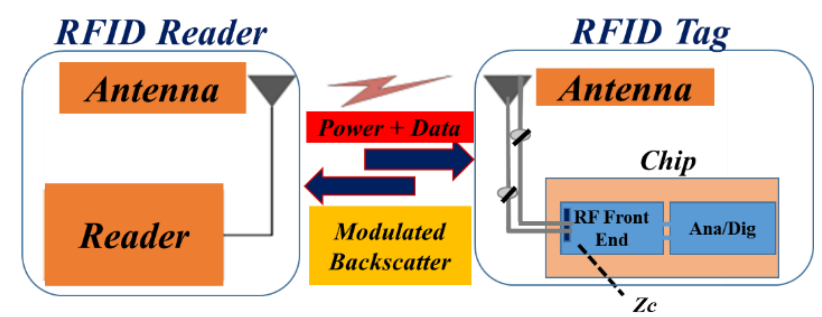

Figure. 1 RFID system based on backscatter communication [8]

The EPC Class 1 Generation 2 standard is responsible for standardizing and defining communication between readers and labels for RFID systems in the UHF frequency band. The communication between readers and labels is started by the reader [6]; The reader sends a continuous wave to wake a group of labels in its interrogation region, then a request asking the tags to respond with their unique IDs; for the uplink (assuming the tag chip remains powered), the tag chip modifies the reflection coefficient of the label antenna by varying its internal impedance $\left(Z_{\text {Chip }}\right.$ $=\mathrm{R}_{\text {Chip }}+\mathrm{j} \mathrm{X}_{\text {Chip }}$ ) to allow reemission of the continuous signal (backscattered modulation). To maximize the efficiency of wireless power transmission, the tag antenna is conceived to be conjugated to the chip's input impedance at its operating frequency [7]. Fig. 1 describes the functioning of a passive UHF-RFID system based on backscatter communication [8].

However, when designing the tag antenna, the impedance matching between the chip and the antenna should be considered to ensure that the tag works properly, as RFID-UHF tags are extensively deployed in a variety of complex environments $[1,2]$. They are often affixed to metal surfaces, the human body, muscle tissue, and other objects with high humidity content. As a result, all these complex application environments have a negative effect on antenna performance, on impedance matching, radiation pattern, read range, and antenna gain [9].Therefore, the antenna-operating environment is the key to the antenna conception.

In addition, the size of the antenna must be reduced as far as possible, with a low manufacturing cost, always keeping a good impedance adaptation and an optimal reading distance. For instance, an RFID tag used as a student-card can be used to record and identify information for various university applications. Nevertheless, the human body also has an extensive impact on a number of previously mentioned antenna parameters. Consequently, the impact of proximity to the body must be thoroughly studied and taken into account when designing the antenna, as the performance of an RFID tag near the
Table 1. RFID bands and their useful characteristics

\begin{tabular}{|c|c|c|}
\hline RFId Bands & $\begin{array}{l}\text { Typical } \\
\text { read } \\
\text { range }\end{array}$ & Main features \\
\hline $\begin{array}{c}\text { LF } \\
125 \mathrm{KHz}\end{array}$ & $30 \mathrm{Cm}$ & $\begin{array}{l}\text { - Short range } \\
\text { - Low data } \\
\text { - Penetrates metal }\end{array}$ \\
\hline $\begin{array}{c}\text { HF } \\
13.56 \mathrm{MHz}\end{array}$ & $1 \mathrm{~m}$ & $\begin{array}{l}\text { - Good range } \\
\text { - Good rate } \\
\text { - Penetrates water }\end{array}$ \\
\hline $\begin{array}{c}\text { UHF } \\
860-960 \\
\text { MHz }\end{array}$ & $\begin{array}{c}<10 \mathrm{~m} \\
\text { for } \\
\text { passive } \\
\text { tags }\end{array}$ & $\begin{array}{l}\text { - Very good range } \\
\text { - High rate } \\
\text { - Penetrates water or } \\
\text { metal... }\end{array}$ \\
\hline $\begin{array}{c}\text { Microwave } \\
2.45 \text { and } 5.8 \\
\text { GHz }\end{array}$ & $\begin{array}{l}\text { Up to } \\
10 \mathrm{~m}\end{array}$ & $\begin{array}{l}\text { - Very good range } \\
\text { - High rate } \\
\text { - Penetrates water or } \\
\text { metal... }\end{array}$ \\
\hline
\end{tabular}

chest of body is degraded significantly in the UHF band.

As part of this study, a number of studies using numerous methods and approaches have been conducted in recent years to design and develop antennas for RFID labels, and finally to simulate the impact of the body on the tag antenna, in order to enhance the performances (gain and reading range) of the RFID tag, when it is fixed to the human body. $[10,11-17]$.

Marrocco [10] was one of the first researchers to study an RFID tag operating in the UHF band positioned near the human body. A suspended patch antenna with an embedded slot has been proposed to enhance the performance of the tag when it is affixed to or near the human body. Deavours presented a theory that uses simple circuits to design a dipole Tmatched antenna for optimal bandwidth [11]. He also developed an impedance matching method to optimize bandwidth, so that the tag can work in different RFID operating bands. Occhiuzzi, Cippitelli and Marrocco [12] described a new label geometry using combined folded dipoles and adjusting slots for portable RFID sensor tag applications. The proposed tag is the same size as a standard credit card and may be affixed or placed on any body part. In Chiu and Tsai [13] study, a loop antenna powered by modified T-matching was proposed. The reading distance of the proposed antenna varied from 3.3 to $6 \mathrm{~m}$, depending on the placement of the tag in different 
positions on the human body in the open space. Amendola and Marocco [14] have proposed a battery-assisted RFID tag for an application for monitoring RFID tags on the human body; however, this method is effective in increasing the reading range, but the major disadvantage is the increased cost and thickness (profile) of the tag. Svanda and Polivka [15] applied the short-circuited vertical folded coupled patch cavity technique to obtain a compact size of the tag. When the tag is attached to a human chest, it can reach a reading range of $5.1 \mathrm{~m}$ and $5.6 \mathrm{~m}$ in free space. Waris [16] propose a passive UHF tag antenna, it was designed by a split ring structure electromagnetically optimized to operate close to the human body. The results showed that the tag offered stable performance at different distances from the body and could easily be integrated into the clothing. The tag can provide a read range that varies from 2 to $4 \mathrm{~m}$ in the UHF bandwidth, when attached to the human body. The reading distance depends on the thickness of the substrate used, either $2 \mathrm{~mm}$ or 5 $\mathrm{mm}$. Ying She [17] presents a new UHF-RFID tag antenna with elliptical loop with a total area of $72 \mathrm{x}$ $30 \mathrm{~mm}^{2}$; it can be used on both the body and the water surfaces. The maximum measured reading range of the label antenna on human body surfaces can be up to $5 \mathrm{~m}$.

Most of these antennas presented above use thick substrates, either very complex structures or ground planes to improve the performance of the tag when it is placed close to the human body. These techniques used to decrease the effect of the human body make labels more expensive and overloaded in terms of profile. Therefore, designing small antennas that can operate in the presence of the human body without reducing the reading range while remaining discreet and economical is a challenging challenge for passive tags at the UHF range.

A new antenna for RFID tags in UHF band has been provided in this paper, based on a meander structure. The proposed antenna can be applied to the human body surfaces. The tag is made up of a radiation element formed by meandering lines, an inverted T-loop matching network, and side arms. The radiation features of the antenna are analyzed. The results of the simulation demonstrate that the antenna proposed can operate regularly on the surfaces of the human body with a good impedance matching. The benefits of our contribution are as follows: (1) simple and miniature structure, (2) offers an optimal reading distance, and (3) easy adaptation of resonance frequency and impedance by adjusting the parameters of the T-loop. The antenna design and the results of the corresponding simulations will be examined in more detail.
The document is divided and organized into four parts as follows. Part 2 presents the modelling of the antenna in free space. Part 3 will present the results of the simulation of the antenna in free space, while the fourth part will describe the simulation of our antenna with the simplified model of the human body. The dimensions and dielectric properties of the tissues making up the chest are detailed. The same section will discuss the results of the simulations of the antenna mounted on the human body, as well as the test of the reading range of our antenna. The last part of this document presents the conclusion.

\section{Antenna design in free space}

The geometry of the tag antenna is illustrated in Fig. 2. The size of the proposed antenna is obviously reduced compared to a conventional dipole structure by using the meander folding method; the dimensions of the tag are $46 \times 20 \mathrm{~mm} 2$, which are smaller than those of a universal credit card or student ID card. The specific dimensions of the antenna parameters are given in Table 2 .

The antenna is designed on a FR-4 substrate with a thickness of $0.8 \mathrm{~mm}$ (with $\varepsilon \mathrm{r}=4.4, \tan \delta=0.025$ ). The copper lines have a thickness of $35 \mu \mathrm{m}$.

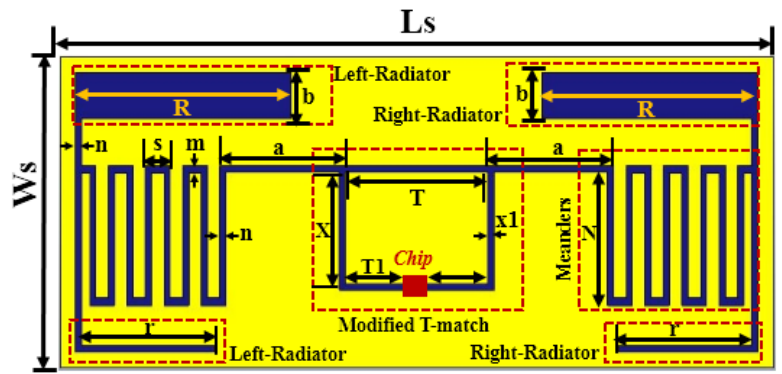

Figure. 2 Geometry of the proposed tag antenna in free space

Table 2. Dimensions of the proposed tag antenna in free

\begin{tabular}{|l|l|l|l|}
\hline Parameter & $\begin{array}{l}\text { Value } \\
(\mathrm{mm})\end{array}$ & Parameter & $\begin{array}{l}\text { Value } \\
(\mathrm{mm})\end{array}$ \\
\hline Ls & 46 & $\mathrm{a}$ & 8 \\
\hline $\mathrm{Ws}$ & 20 & $\mathrm{~b}$ & 3 \\
\hline $\mathrm{T}$ & 9.2 & $\mathrm{x} 1$ & 0.4 \\
\hline $\mathrm{T} 1$ & 4.1 & $\mathrm{R}$ & 13.9 \\
\hline $\mathrm{N}$ & 8.6 & $\mathrm{r}$ & 8.6 \\
\hline $\mathrm{m}$ & 0.5 & $\mathrm{X}$ & 7.2 \\
\hline $\mathrm{n}$ & 0.4 & $\mathrm{~h}$ & 0.8 \\
\hline
\end{tabular}


The antenna consists of a radiation element consisting of a meander-folded line, side radiators and a modified rectangular T-loop.

The dimensions of the matching loop can be easily adjusted, allowing a good adaptation between the impedance of the antenna and that of the chip. We chose the Higgs- 4 chip manufactured by Alien Technology [18], which has an equivalent characteristic impedance of $20.5-\mathrm{j} 191 \Omega$ at $867 \mathrm{MHz}$. The chip packaging used in the design is SOT-323. This type is easy to weld manually. The main advantage of using this chip is the minimum radiofrequency communication power that can reach the $-18.5 \mathrm{dBm}$ level.

Our antenna is composed (1) of a meander-folded dipole, used to load the dipole in order to increase the total length of the half-wave dipole, ensuring both a miniaturization of the antenna, and also a significant shift in the resonance frequency towards the low frequencies without increasing the size of the antenna. Using this method, the size of our antenna has been reduced by $91 \%$ compared to the traditional antenna. (2) Of a T-match network consists of a rectangular loop, and used to easily adapt the antenna impedance to that of the chip, the variation in length and width of the loop line varies the resistance and reactance of the antenna. In our case, the chip impedance is $\mathrm{Zc}=$ 20.5 - j191 $\Omega$ at $867 \mathrm{MHz}$, which has a low resistance but a high capacitive reactance, the use of the Tmatch technique has made impedance matching easier. (3) Left and right side radiators used to improve the reflection coefficient, adjust the antenna resonance frequency and expand the radiation area in order to increase the antenna gain to achieve an optimal reading distance.

To ensure maximum power transfer, the imaginary part of the antenna input impedance must be conjugated to that of the chip. Therefore, the input impedance of the tag antenna should be $20.5+\mathrm{j} 191$ $\Omega$ at $867 \mathrm{MHz}$ [19].

\section{Simulations of the tag in free space}

First, the simulation is carried out in free space. The adaptation between the antenna and the chip is done in free space. Fig. 2 illustrates the dimensions chosen for the antenna adapted to operate in free space in the UHF RFID band. Figs. 3 and 4 demonstrate the simulated reflection coefficient and input impedance of the proposed tag antenna in free space in HFSS (High-frequency structure simulator) (Fig. 4 (a)) and CST (Computer Simulation Technology) (Fig. 4 (b)). Table 3 summarizes the results obtained, the reflection coefficient and input impedance of the antenna in free space.
The antenna design and simulation results obtained are performed by CST and verified by another electromagnetic software, HFSS, in order to validate the simulation results. These results are illustrated in Figs. (3 and 4); we can see that we have a good agreement between the two results, either at the level of the reflection coefficient or the input impedance of the antenna.

\section{Simulations of the tag on the human body}

After simulating the antenna (without PVC card) in free space, we adjusted the parameters of the lateral arms of our antenna to make it work on the surfaces of the human body (hand and arm chest), by taking into account the effects caused by the proximity of the human tissue, the absorption of electromagnetic waves on the input impedance, the radiation pattern, the gain and the reading distance.

The identification tag antenna is embedded on a PVC (polyvinyl chloride) plastic substrate with a dielectric constant (Er) of 2 and a loss tangent of 0.0013 . The dimensions of the PVC card are $60 \times 30$ $\mathrm{x} 2 \mathrm{~mm}^{3}$. It is a miniaturized and sophisticated card, easy to put in the pocket and wallet.

In this part, the identification card is positioned close to and in the centre of a simplified reference model of the human body in the form of a $400 \mathrm{~mm}$ thick stratified cylinder [20]. The distance $\mathrm{h}$ between the label and the human body model is set at $\mathrm{h}=5$ $\mathrm{mm}$, which is similar to the real conditions, as shown in Fig. 5. The approximate model consists of a stratified elliptical cylinder whose electromagnetic parameters and electrical properties of the layers (skin, fat, muscle and bone) such as dielectric constant, loss tangent and conductivity around 867 $\mathrm{MHz}$ are presented in Table 4 [14, 20-22] and which have been obtained from the analysis of the

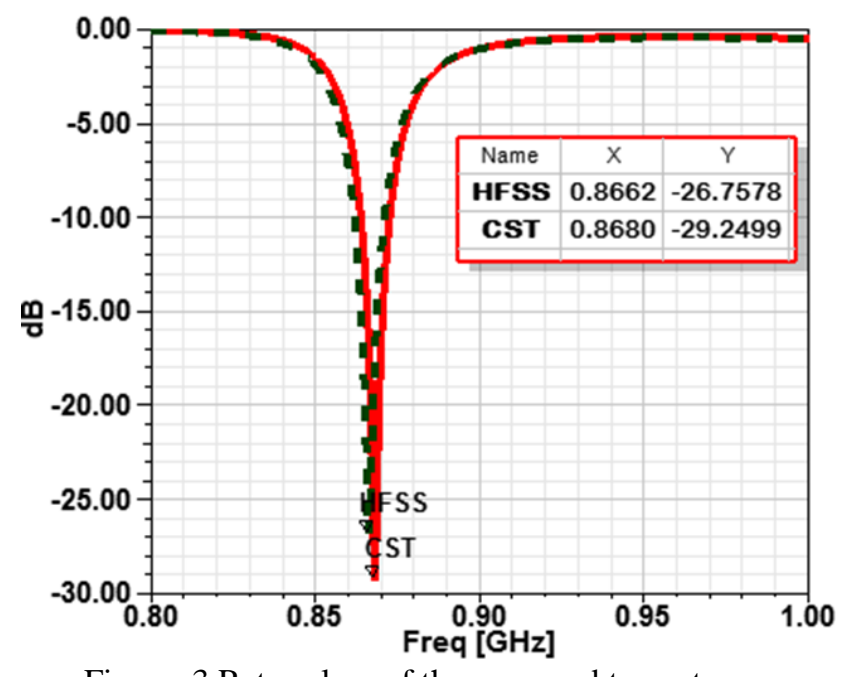

Figure. 3 Return loss of the proposed tag antenna designed in free space 
Table 3. Simulation results on CST and HFSS in free

\begin{tabular}{|c|c|c|c|}
\hline Simulator & $\begin{array}{c}\text { Resonant } \\
\text { frequency } \\
{[\mathbf{M H z}]}\end{array}$ & $\begin{array}{c}\text { Return } \\
\text { loss } \\
{[\mathbf{d B}]}\end{array}$ & $\begin{array}{c}\text { Input } \\
\text { impedance } \\
{[\mathbf{\Omega}]}\end{array}$ \\
\hline CST & 866.2 & -26.75 & $\begin{array}{c}\mathrm{Z}=23.4+ \\
\mathrm{j} 193.52\end{array}$ \\
\hline HFSS & 868 & -29.24 & $\begin{array}{c}\mathrm{Z}=22.4+ \\
\mathrm{j} 192.7 \Omega\end{array}$ \\
\hline
\end{tabular}

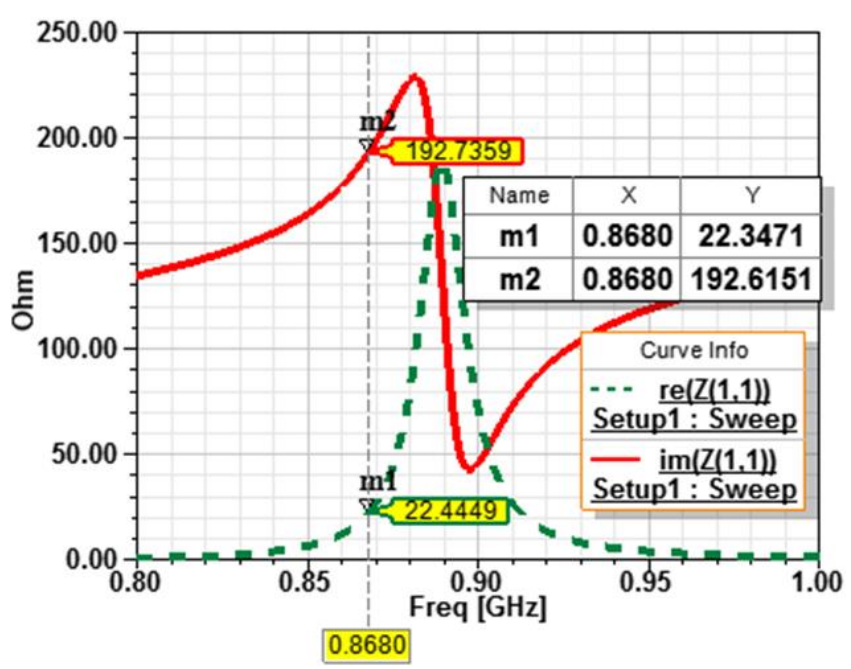

(a)
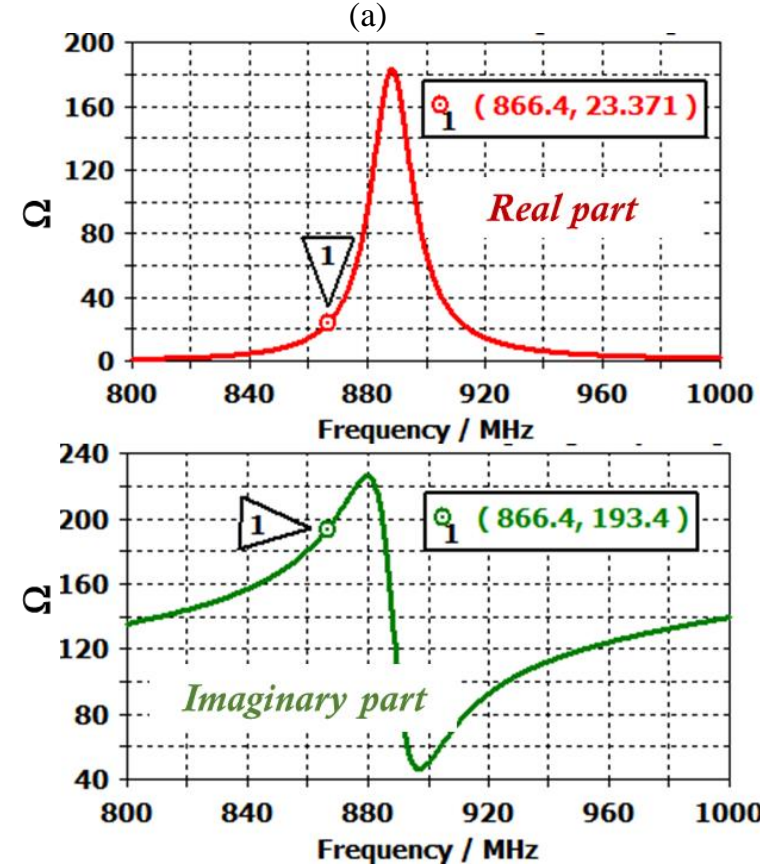

(b)

Figure. 4 Simulated Input impedance of the proposed tag antenna in: (a) HFSS and (b) CST

anatomical maps in [20]. All simulations are performed using CST software, verified and compared by HFSS.

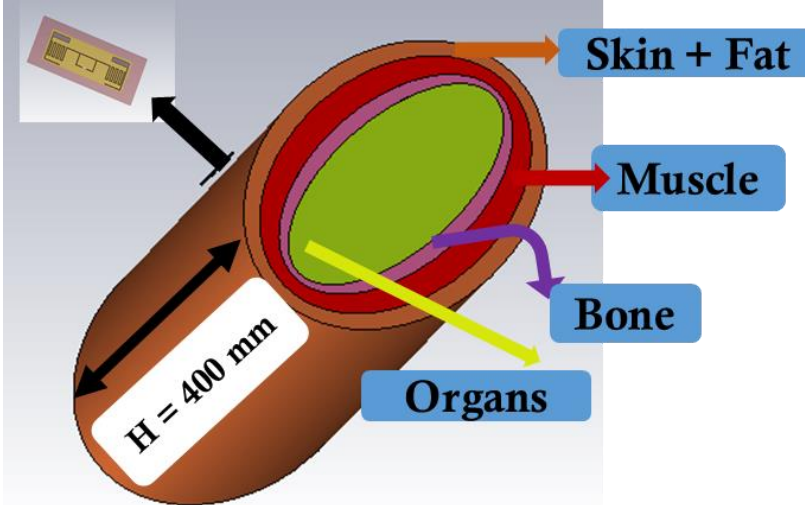

Figure. 5 Schematic perspective view of the proposed tag antenna mounted on approximate human body model

Table 4. Physical parameters of the human body model $[14,20-22]$

\begin{tabular}{|c|c|c|c|}
\hline Layer & $\begin{array}{c}\text { Relative } \\
\text { permittivity }\end{array}$ & $\begin{array}{c}\text { Conductivity } \\
(\mathbf{S} / \mathbf{m})\end{array}$ & $\begin{array}{c}\text { Thin Man } \\
\left(\mathbf{m m}^{2}\right)\end{array}$ \\
\hline Skin + Fat & 14.42 & 0.24 & $335 \times 168$ \\
\hline Muscle & 54.95 & 0.95 & $310 \times 142$ \\
\hline Bone & 20.76 & 0.34 & $284 \times 105$ \\
\hline Organs & 52 & 0.93 & $272 \times 84$ \\
\hline
\end{tabular}

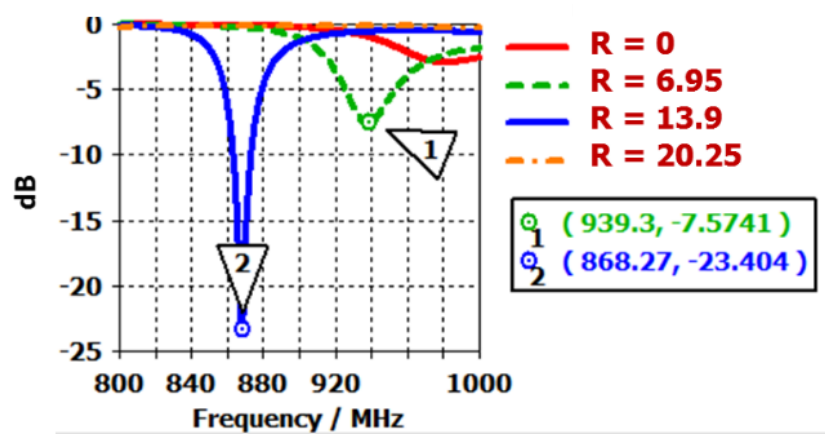

Figure. 6 The simulated return loss of the proposed tag antenna with different values of $(\mathrm{R})$

We conducted a parametric study to examine the effect of the parameter on impedance matching (reflection coefficient and input impedance) in order to operate the antenna on the surface of the human body. The key parameter that led to the working of the antenna mounted on the surface of the human body is the variation in the width " $\mathrm{R}$ " of the two large side radiators.

Fig. 6 shows that the resonance frequency shifts towards the low frequencies, when the length " $R$ " of the two radiators (right and left) is increased at the same time, while in the absence of these two radiators, there is no impedance matching. 


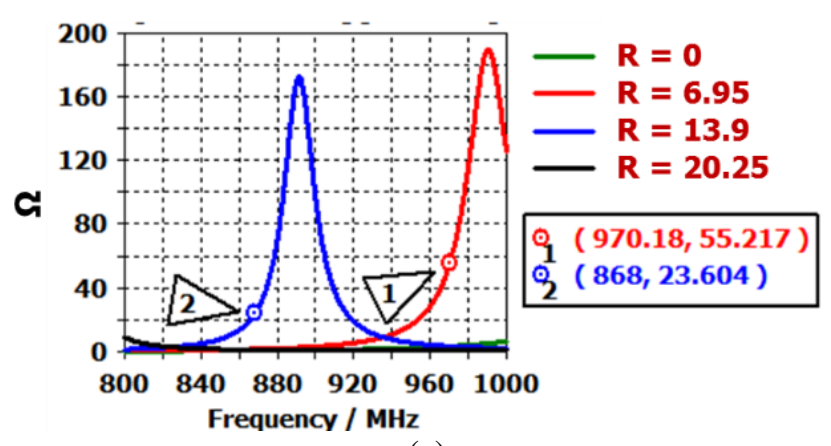

(a)

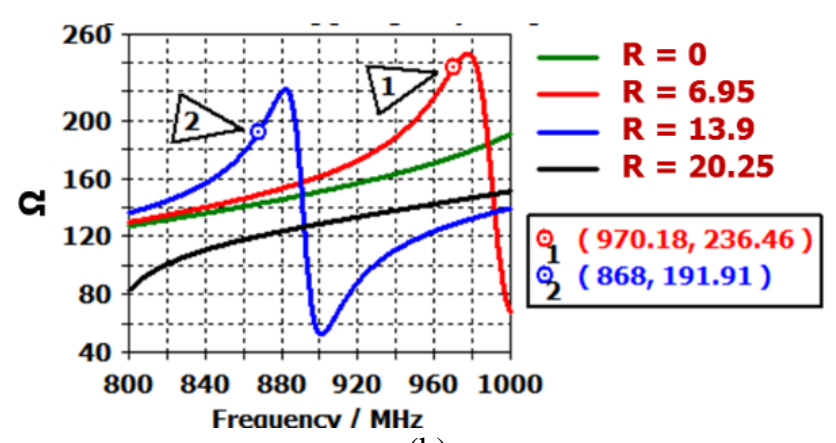

(b)

Figure. 7 The Simulated input impedance of the proposed tag antenna with different values of (R): (a) the real part and (b) the imaginary part of the impedance

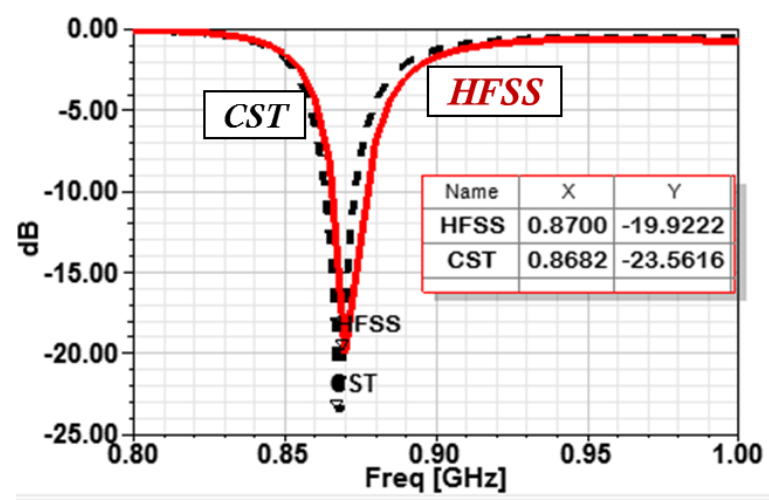

Figure. 8 Return loss of the proposed tag antenna mounted on human body

When the radiators are present with $\mathrm{R}=13.9 \mathrm{~mm}$, the tag resonance frequency is $868 \mathrm{MHz}$. The reflection coefficient is less than $-22 \mathrm{~dB}$, which indicates that the impedance of the chip and tag antenna provides a good impedance matching at the frequency $868 \mathrm{MHz}$.

Fig. 7 shows that the real and imaginary parts of the antenna input impedance increase when " $R$ ", increases, in the absence of radiators (when $R=0$ ) the antenna impedance increases to $Z=0.76+\mathrm{j} 142 \Omega$ at $868 \mathrm{MHz}$. When $\mathrm{R}=13.9 \mathrm{~mm}$, the antenna impedance reaches the value $\mathrm{Z}=23.6+\mathrm{j} 191.9 \Omega$, which shows that our antenna is well adapted to the Higgs-4 chip at the resonant frequency $868 \mathrm{MHz}$.
Fig. 8 shows the reflection coefficient of the proposed tag Antenna when it is mounted on the human body, simulated on CST and verified by the HFSS. After adjusting and optimizing the parameters of our antenna to mount it on the human body. The antenna has reached a reflection coefficient of about $-19.92 \mathrm{~dB}$ at frequency $870 \mathrm{MHz}$ on HFSS, and $23.56 \mathrm{~dB}$ at $868.2 \mathrm{MHz}$ on CST, which shows that the antenna is well adapted and can operate in human body surface without any problems. The bandwidth ranges from 865 to $870 \mathrm{MHz}$, which covers the operating bands used in Europe and Africa (Morocco).

Fig. 9 presents the proposed tag antenna input impedance against frequency obtained by CST and HFSS. From the graphs, we can see that the input impedance of antenna is equal to Zant $=23.9+\mathrm{j} 192.3$ $\Omega$ at $868.2 \mathrm{MHz}$ obtained in CST, which is almost conjugated to the impedance of the chip Zch $=20.5$ j191 $\Omega$. Concerning HFSS, we obtained an impedance value of Zant $=15.18+\mathrm{j} 184.9$ at frequency $870 \mathrm{MHz}$. we notice that we have a small difference between the two results; this is due to the mesh size of each simulator.

These results were obtained after a parametric study carried out on certain parameters of the adaptation circuit, in order to optimize the parameter values.

We have deduced that some parameters of our antenna affect the real part of the input impedance, while some parameters affect the imaginary part or both parts at the same time (as in the case of the width ' $R$ '" of the radiator). After this study, we optimized the antenna to have a miniature size, good impedance matching, good gain and long read range, when the antenna is mounted on surfaces of the human body. Table 5 summarizes the results obtained, the reflection coefficient and input impedance of the antenna when the tag antenna is mounted in human body surfaces.

Fig. 10 shows the radiation patterns of the tag antenna on the surface of the human body at the resonant frequency of $867 \mathrm{MHz}$. We can see that most of the energy radiated by the tag antenna is absorbed into the human body because it is conductive.

Fig. 11 shows the gain achieved by the proposed antenna, simulated by CST and compared by HFSS. The simulated results of our tag antenna are both precise and satisfactory. As a result, the gain realized when the tag is mounted on the human body reaches a value of $-1.85 \mathrm{~dB}$ on CST and $-1.54 \mathrm{~dB}$ on HFSS at $867 \mathrm{MHz}$ for the proposed antenna design. 

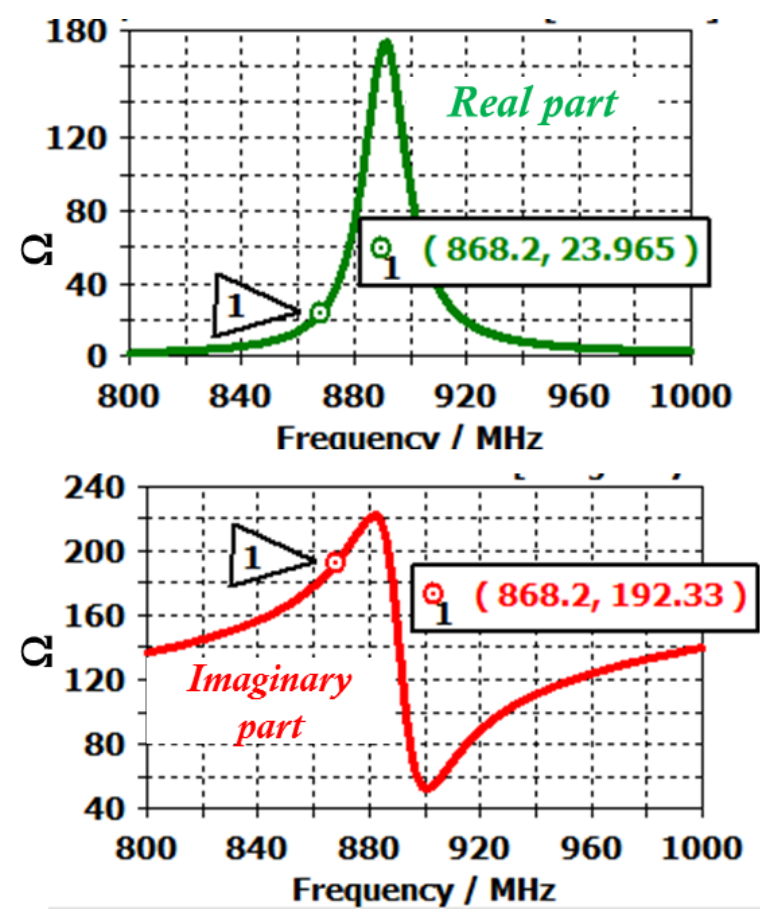

(a)

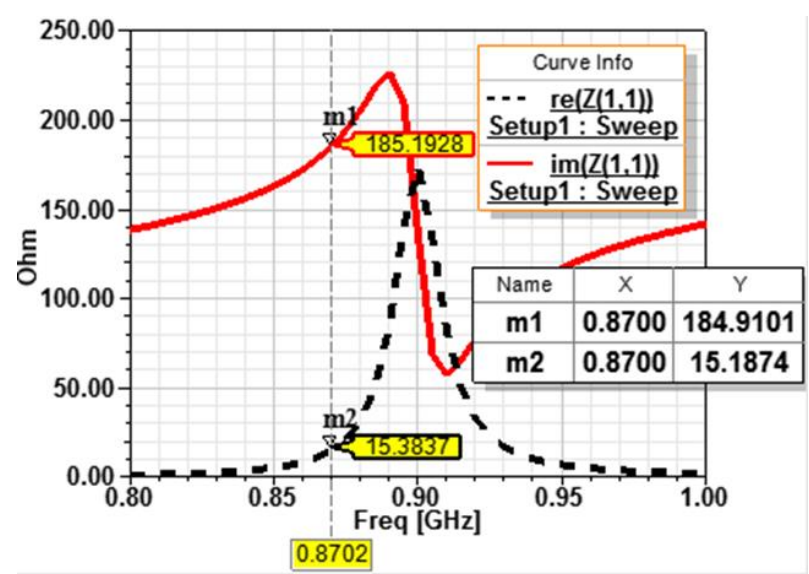

(b)

Figure. 9 Input impedance of the proposed tag antenna mounted on human body in: (a) HFSS and (b) CST

Table 5. Simulation results on CST and HFSS (Tag mounted on the human body)

\begin{tabular}{|c|c|c|c|}
\hline Simulator & $\begin{array}{c}\text { Resonant } \\
\text { frequency } \\
{[\mathrm{MHz}]}\end{array}$ & $\begin{array}{c}\text { Return } \\
\text { loss } \\
{[\mathbf{d B}]}\end{array}$ & $\begin{array}{c}\text { Input } \\
\text { impedance }\end{array}$ \\
\hline CST & 868.2 & -23.56 & $\begin{array}{c}\mathrm{Z}=23.9+ \\
\mathrm{j} 192.3 \Omega\end{array}$ \\
\hline HFSS & 870 & -19.92 & $\begin{array}{c}\mathrm{Z}=15.18+ \\
\mathrm{j} 184.9 \Omega\end{array}$ \\
\hline
\end{tabular}

After simulating the tag antenna, we made the prototype of our antenna with the LPKF machine, then we soldered our chip (Alien Higgs-4 SOT-323) with the antenna, in order to measure the reading distance between the RFID-UHF reader and our tag. The prototype of the manufactured tag antenna is shown in Fig. 12-(a) and Fig. 12-(b) shows the view of the antenna and placement of the Higgs-4 chip using X-rays.

The read range is an important parameter in the design of an RFID tag; it corresponds to the maximum distance at which the tag receives the minimum threshold power necessary to wake it up and send a feedback signal, which means the maximum distance at which the reader can detect this response signal.

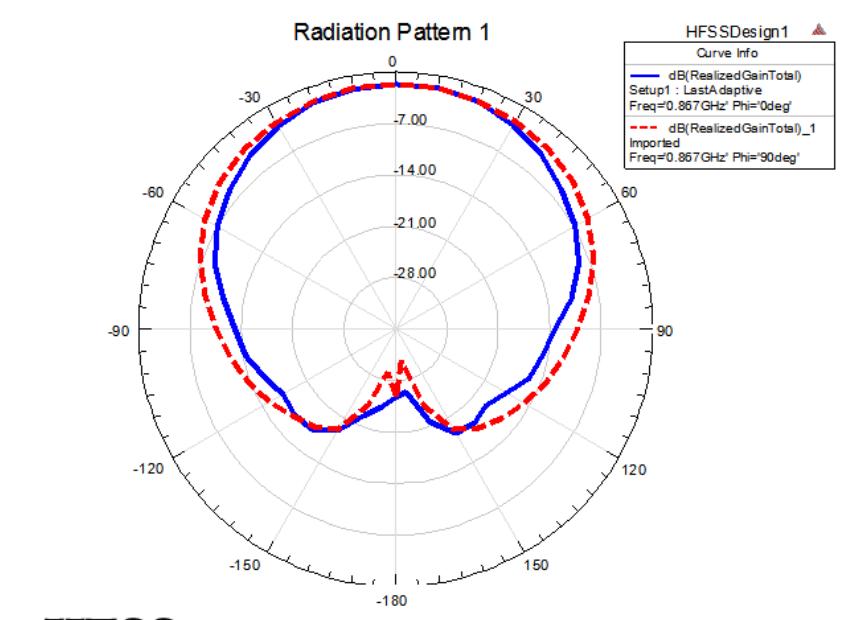

\section{HFSS}

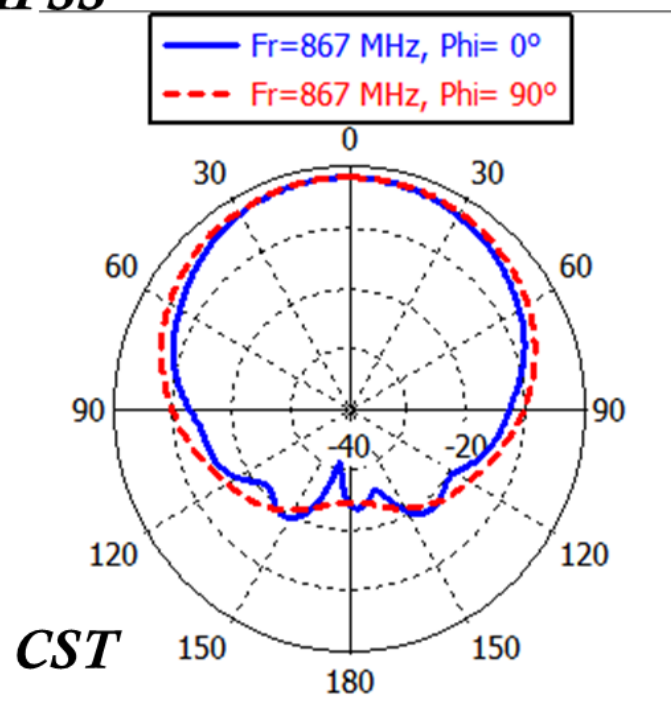

Figure. 10 Radiation pattern from the tag antenna mounted on the human body

The read range of the tag can be calculated using the Friis equation (Eq. (1)) [5]:

$$
d=\frac{\lambda}{4 \pi} \cdot \sqrt{\frac{E I R P_{R} \cdot \tau \cdot G_{t}}{P_{c}}}
$$



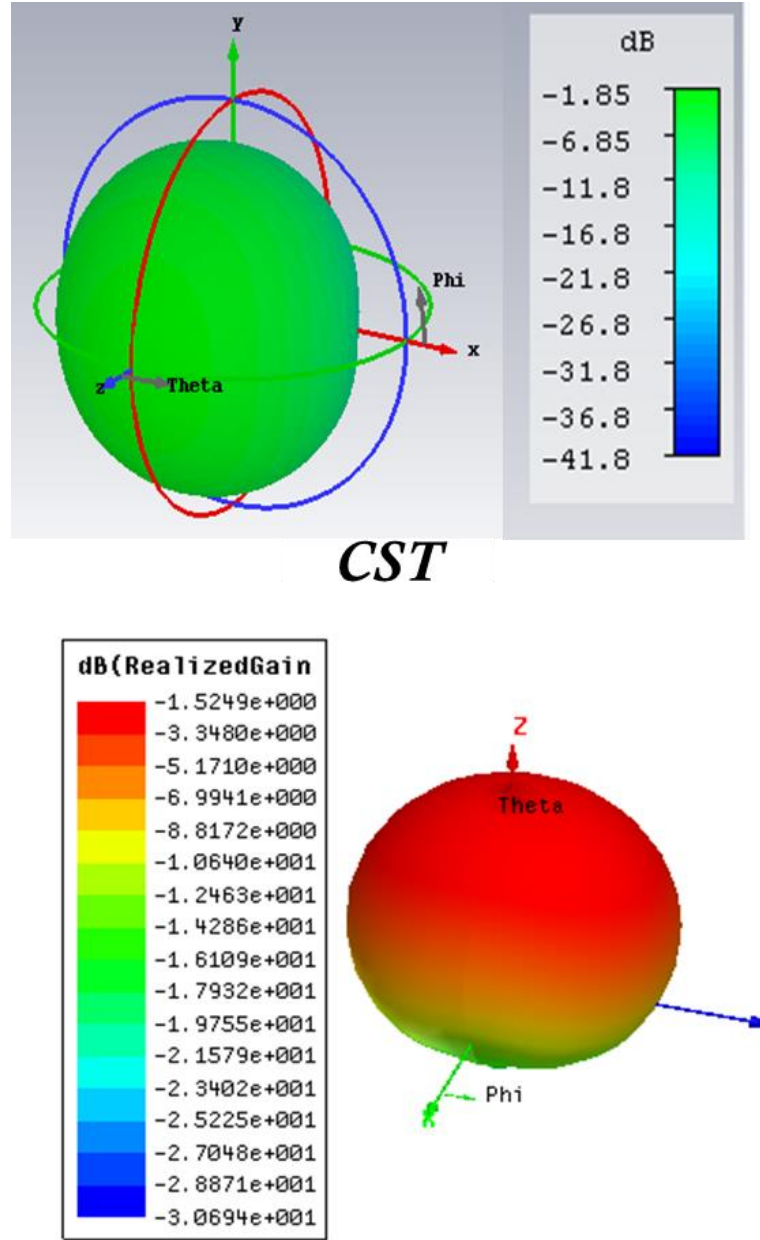

\section{HFSS}

Figure. 11 Simulated 3D radiation pattern at $867 \mathrm{MHz}$ for the proposed antenna mounted on the human body

Where EIRPR is the effective power transmitted by the reader (or EIRP $P_{R}=P_{r} \times G_{r}$, where $P_{r}$ is the power transmitted by the reader, and $G_{r}$ is the gain of the emitting antenna). $P_{c}$ is the sensitivity of the tag, it is the minimum threshold power required to activate the chip and to perform back-scattering modulations, and $\mathrm{G}_{\mathrm{t}}$ is the tag gain [23].

Using this formula, we can calculate the maximum distance at which the reader can detect the tag, with a minimum output power required for chip activation of $-18.5 \mathrm{dBm}$ and an effective isotropic radiated power $\left(E{ }_{R} P_{R}\right)$ of the signal transmitted by the reader is 3.24 Watt in Europe. The maximum theoretical reading distance of the tag antenna placed on the surface of the human body is $10.4 \mathrm{~m}$.

In order to confirm the theoretical results, the proposed antenna was placed on the hands and near to the chest in an environment with no free space. As shown in Fig. 13, the metal medium was maintained in the measurement laboratory, creating a closed environment. The reading range was measured using

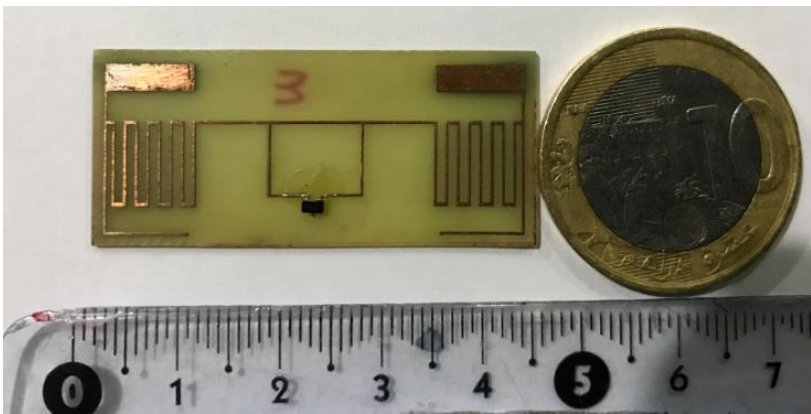

(a)

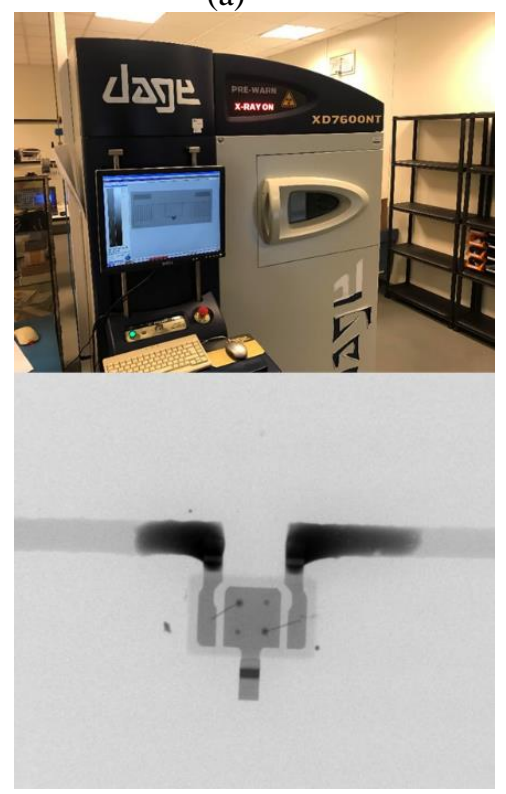

(b)

Figure. 12 (a) The prototype of the manufactured tag antenna and (b) view of the antenna and the chip with Xrays

the configuration shown in Fig. 13. We used a fixed RFID-UHF reader (F5860-H) with 4 ports offering a power of $30 \mathrm{dBm}$, manufactured by Shenzhen Sanray Technology Co, Ltd. and connected to two circular polarized transmitting antennas having a gain of 8 $\mathrm{dBi}$, and operating in the FCC ISM (902-928 MHz) and ETSI (865.6-867.6 MHz) bands. The measured reading range is around $6 \mathrm{~m}$. It is lower than the theoretical reading range due to the manufacturing and assembly error of the chip, as well as the type of the measurement environment (presence of an X-ray machine, metal surfaces). However, the read range still meets the requirements of the worst-case scenario. Therefore, this result may therefore vary depending on environmental conditions.

Table 6 compares the total dimensions and reading range of our tag with the results previously published in the literature. Our design offers a small size in terms of volume and a large reading range even when it is mounted on the surface of the human body. 
Table 6. Comparison of tag size and measuring range

\begin{tabular}{|c|c|c|c|}
\hline Tags & $\begin{array}{c}\text { Dimensions } \\
{\left[\mathrm{mm}^{3}\right]}\end{array}$ & Power & $\begin{array}{l}\text { Read range } \\
\text { (tag on the } \\
\text { human } \\
\text { body) }\end{array}$ \\
\hline $\begin{array}{c}\text { Tag 1: } \\
\text { [24] }\end{array}$ & $80 \times 50 \times 0.2$ & $3.2 \mathrm{~W}$ & $4.6 \mathrm{~m}$ \\
\hline $\begin{array}{c}\text { Tag 2: } \\
{[16]}\end{array}$ & $\Pi \times 40 \times 40 \times 2$ & $3.28 \mathrm{~W}$ & $4 \mathrm{~m}$ \\
\hline $\begin{array}{c}\text { Tag 3: } \\
\text { [17] }\end{array}$ & $72 \times 30 \times 0.8$ & $4 \mathrm{~W}$ & $5 \mathrm{~m}$ \\
\hline $\begin{array}{c}\text { Proposed } \\
\text { tag }\end{array}$ & $46 \times 20 \times 0.8$ & $3.28 \mathrm{~W}$ & $6 \mathrm{~m}$ \\
\hline
\end{tabular}

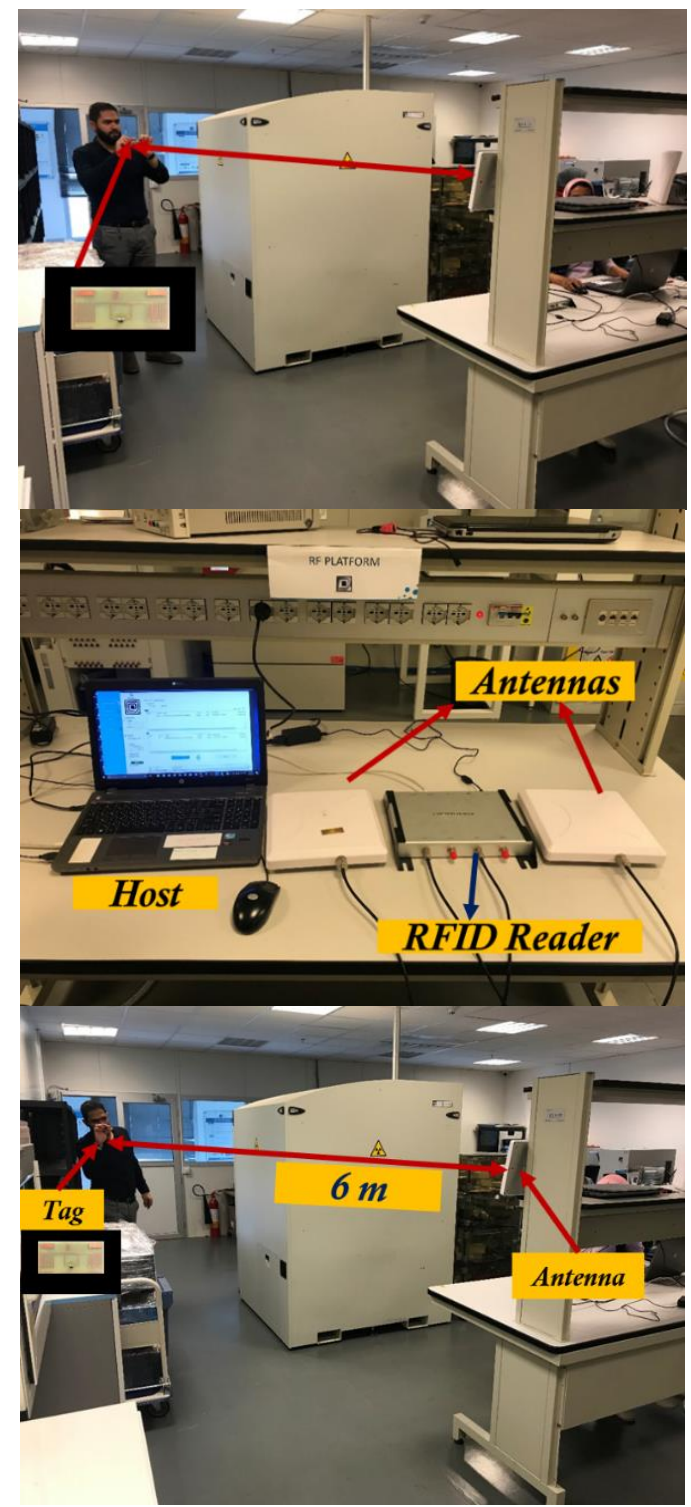

Figure. 13 Experimental RFID equipment for measuring the read range

\section{Conclusion}

A new antenna for RFID tags in the UHF band has been proposed in this paper. The proposed antenna can be applied to the surfaces of the human body. The tag is composed of a radiation element made up of meander lines, an inverted T-matching network and side arms. The proposed RFID antenna has a small size $46 \times 20 \times 0.8 \mathrm{~mm}^{3}$ miniaturized by 91\% compared to the theoretical dimensions. The simulation results show that the proposed antenna can operate correctly on the surfaces of the human body with a good impedance matching. The advantages of our contribution include a simple and miniature structure, an optimal reading distance and an easy adaptation of the resonance frequency and impedance by adjusting the antenna parameters. The reading range is about $6 \mathrm{~m}$ when the tag is positioned on the chest or held in the hand. Finally, our proposed tag will be integrated into the PVC card and can be used on identification cards for various applications.

\section{Acknowledgments}

The authors would like to thank Ms. Ilham Bouzida, head of the microelectronics department of the Moroccan Foundation for Advanced Research and Innovation (MASCIR), for their kind support in the framework of the measurement experiment.

\section{References}

[1] V. Chawla and H. Dong-Sam, "An overview of passive RFID", IEEE Communications Magazine, Vol. 45, No. 9, pp. 7-11, 2007.

[2] K. Finkenzeller, "RFID Handbook", Fundamentals and Applications in Contactless Smart Cards and Identification, 2nd ed. JohnWiley and Sons, Hoboken, NJ, 2003.

[3] Y. El hachimi, and A. Farchi, "A Novel Compact Antenna for Passive UHF RFID Tag Using $\pi$-Match and Meander Techniques", In: Third International Conference on Computing and Wireless Communication Systems (ICCWCS), 2019.

[4] S. Tedjini and E. Perret, "Radio-Frequency Identification Systems and Advances in Tag Design", The Radio Science Bulletin, No. 33, December 2009.

[5] K. V. S. Rao, P. V. Nikitin, and S. F. Lam, "Antenna design for UHF RFID tags: a review and practical application", IEEE Trans. Antennas Propagation, Vol. 53, No. 12, pp. 3870-3876, 2005. 
[6] S. Roy, V. Jandhyala, J.R. Smith, D. J. Wetherall, B. P. Otis, R. Chakraborty, M. Buettner, D. Yeager, Y.C. Ko, and A. Sample, "RFID: From Supply Chains to Sensor Nets", In: Proc. of the IEEE, Vol. 98, No. 9, pp. 1583-1592, 2010.

[7] J. C. Bolomey, S. Capdevila, L. Jofre, and J. Romeu, "Electromagnetic Modeling of RFIDModulated Scattering Mechanism. Application to Tag Performance Evaluation", In: Proc. of the IEEE, Vol. 98, No. 9, pp. $1555-1569,2010$.

[8] J. Zhang, G.Y. Tian, A. M. J. Marindra, A. I. Sunny, and A. B. Zhao, "A Review of Passive RFID Tag Antenna-Based Sensors and Systems for Structural Health Monitoring Applications", Sensors journal, Vol. 17, No. 2, 2017.

[9] M.H. Lin and C.W. Chiu, "Human-body effects on the design of card-type UHF RFID tag antennas", In: IEEE-AP/URSI Symposium, pp. 521-524, 2011.

[10] G. Marrocco, "RFID antennas for the UHF remote monitoring of human subjects", IEEE Trans Antennas Propagation, Vol. 55, pp. 18621870, 2007.

[11] D.D. Deavours, "Analysis and design of wideband passive UHF RFID tags using a circuit model", In: Proc. of IEEE International Conference on RFID, pp. 283-290, 2009.

[12] C. Occhiuzzi, S. Cippitelli, and G. Marrocco, "Modeling, design and experimentation of wearable RFID sensor tag", IEEE Trans. Antennas Propagation, Vol. 58, pp. 2490-2498, 2010.

[13] C.W. Chiu, M-C. Tsai, H-C Wang, and TF. Wu, "Broadband T-matching loop tag antenna design for on-body UHF RFID applications", Microwave Optical Tech. Letter, Vol. 56, pp. 1194-1200, 2014.

[14] S. Amendola, G. Bovesecchi, A. Palombi, P. Coppa, and G. Marrocco, "Design, Calibration and Experimentation of an Epidermal RFID Sensor for Remote Temperature Monitoring", IEEE Sensors Journal, Vol. 16, No. 19, pp. 7250-7257, 2016.

[15] M. Svanda and M. Polivka, "On-body semielectrically-small tag antenna for ultra-high frequency radio-frequency identification platform-tolerant applications", IET Microwaves Antennas \& Propagation, Vol. 10, No. 6, pp. 631-637, 2016.

[16] B. Waris, L. Ukkonen, J. Virkki, and T. Björninen, "Wearable passive UHF RFID tag based on a split ring antenna", In: Radio and Wireless Symposium (RWS formerly RAWCON), pp. 55-58, 2017.
[17] Y. She, T. Tang, G.J. Wen, and H.R. Sun, "Ultra-high-frequency radio frequency identification tag antenna applied for human body and water surfaces", Int. Journal of RF and Microw. Comput. Aided Eng., Vol. 29, No. 1, 2019.

[18] Higgs 4 IC Datasheet, “An EPCglobal Complaint Class-1 Gen-2 ISO/IEC 18000-6C UHF RFID Integrated Circuit", Alien Technology, 2017.

[19] C. Occhiuzzi, C. Paggi, and G. Marrocco, "Passive RFID strain-sensor based on meanderline antennas", IEEE Trans. Antennas Propagation, Vol. 59, pp.4836-4840, 2011.

[20] "Dielectric properties of body tissues," niremf.ifac.cnr.it/tisspro/.

[21] A. Dubok and A. Smolders, "Miniaturization of robust UHF RFID antennas for use on perishable goods and human bodies", IEEE Antennas Wireless Propag. Letter, Vol. 13, pp. 1321-1324, 2014.

[22] S. Gabriel, R. Lau, and C. Gabriel, "The dielectric properties of bio-logical tissues: III. Parametric models for the dielectric spectrum of tissue", Phys. Med. Biol., Vol. 41, pp. 22712293, 1996.

[23] Y. Gmih and A. Farchi, "A New Design of a Miniaturized UHF-RFID Passive Tag Antenna Based on L-Shape Radiators with Meandered Dipole", In: Proc. of the 3rd International Conference on Computing and Wireless Communication Systems (ICCWCS), 2019.

[24] D. Marques, M. Egels, and P. Pannier, "Broadband UHF RFID Tag Antenna for BioMonitoring", Progress In Electromagnetics Research B, Vol. 67, pp. 31-44, 2016. 